\title{
Absorption of X-Rays in Air
}

\author{
By Frank H. Day and Lauriston S. Taylor
}

\begin{abstract}
Studies have been undertaken to determine the absorption in air of X-rays produced by voltages from 10 to $200 \mathrm{kv}$ (constant potential) for various initial filtrations. A free-air ionization chamber on tracks is used to obtain absorption data over a 150-cm distance. No appreciable change in quality of X-rays is observed in this distance because of the air absorption. Hence, for short distances, effective air absorption coefficients for heterogeneous $\mathrm{X}$-rays of various qualities have been determined.
\end{abstract}

\section{Introduction}

The use, in recent years, of beryllium-window X-ray tubes with their high-intensity outputs of soft X-rays has developed a need for air-absorption corrections where distance is a factor in X-ray exposure measurements. Such, for example, is the case where the inverse-square law is used in computing the exposure at a point when the actual measurement is of necessity made at some other point. There is also need for corrections to be applied to the free-air type of ionization chamber due to air absorption between the limiting diaphragm of the chamber and the front edge of the collector plates. Since the exposure rate is specified in the plane of the limiting diaphragm, air-absorption along the path between the diaphragm and the collector plate results in the readings of the chamber being too low. This distance in the case of the guarded-field free-air standard for calibrations up to $200 \mathrm{kv}$ at the Bureau of Standards is $21.1 \mathrm{~cm}$, and for unfiltered radiations produced at, say, $50 \mathrm{kv}$, the necessary corrections may be considerable.

\section{Apparatus and Experimental Procedure}

A diagram of the experimental arrangement is shown in figure 1, where a mobile, free-airguard-plate ionization chamber is indicated. The opening in its lead shield is $10 \mathrm{~cm}$ in diameter. This opening is adequate to accommodate, at any point along the track, the total area of X-rays determined by the fixed, limiting diaphragm, the diameter of which is $1.75 \mathrm{~cm}$. The effective width of the collector plates is $10.2 \mathrm{~cm}$, and the diameter of the beam with the chamber in its farthest position from the tube (position $B$, fig. 1) is $6.5 \mathrm{~cm}$. The interelectrode separation is a fixed distance of $12.7 \mathrm{~cm}$, and this is insufficient spacing to allow for the production and collection of all secondary electrons associated with a primary beam $6.5 \mathrm{~cm}$ in diameter. Hence, there is a slight loss of ionization, which earlier studies show does not exceed 1 or 2 percent. ${ }^{1}$ No correction has been applied for this loss.

The charge collected in the ionization chamber at various points along the track is measured with a capacity compensator and string electrometer ${ }^{2}$ with an accuracy of \pm 1 percent. The exposure of the chamber is controlled by a timer operating a $1 / 2-i n$. lead shutter. The timer is actuated by an accurately controlled 60-cycle signal from the Radio Section of the Bureau of Standards.

Tungsten-target X-ray tubes with low inherent filtration are used in conjunction with various types and thicknesses of initial filtration. The term "initial filtration," as here used, refers to filters of aluminum, copper, or lead introduced between the X-ray tube and the column of air over which air-absorption measurements are made. The window thickness of the cerium glass in one $\mathrm{X}$-ray tube used is $1.29 \mathrm{~mm}$ and of the beryllium in another tube, $1.5 \mathrm{~mm}$.

Power supplied to the X-ray tube is furnished by a kenotron rectifier with a resistance-capacitance filter incorporated to reduce the ripple to

\footnotetext{
Lauriston S. Taylor, George Singer, and A. L. Charlton, Am. J. Roent. 41, 256 (1939).

${ }^{2}$ Lauriston S. Taylor, BS5. Research 6, 807 (1931) RP306.
} 


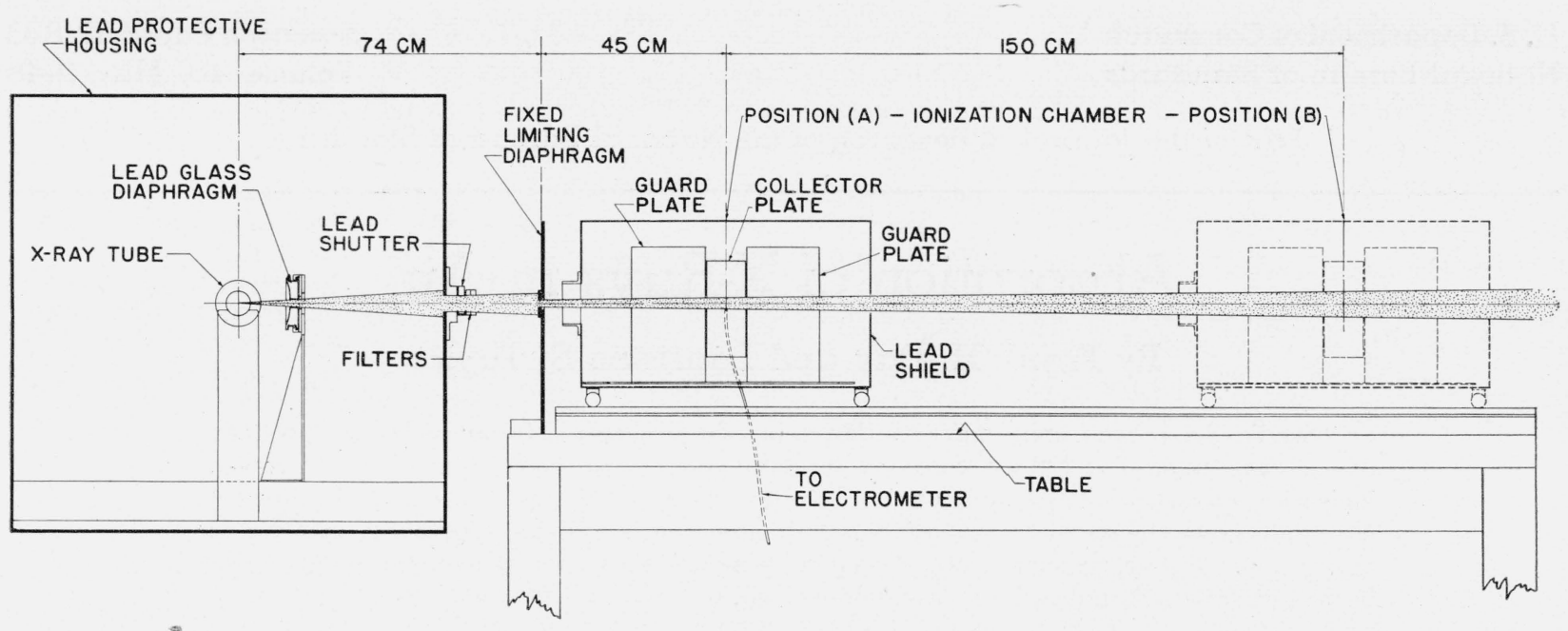

Figure 1. Experimental arrangement for air absorption measurements.

0.05 percent per milliampere current drain. The tube currents used are not in excess of $10 \mathrm{ma}$.

The voltage input to the rectifier units is constant to 0.25 percent or better, the 208 -volt commercial supply being fed through a voltage stabilizer. The voltage to the rectifier units is then varied by induction regulator control. It is estimated that the absolute direct-current voltage applied to the X-ray tubes is known to an accuracy of 1 or 2 percent.

The filament voltage of the X-ray tubes is stabilized by an electronic voltage stabilizer in the ground circuit feeding through an insulating transformer. The output of the stabilizer is also manually controlled by an adjustable-ratio autotransformer to reduce long-period fluctuations.

In view of the above-described stabilization, the variation in quantity of X-ray output over a period of exposure of 10 seconds or more is not greater than 0.5 percent. This is also verified from previous experience on fluctuations in X-ray output of this equipment, as determined by the Bureau's standard chamber for measurements up to $200 \mathrm{kv}$.

\section{Observations and Calculations}

Under steady operating conditions of the X-ray tube, the ionization chamber is exposed for a given number of milliampere-seconds at successive points along the track. The ratio of the ionization currents measured at two points along the track is a measure of the air absorption between these points, inasmuch as the total flux passing through the limiting diaphragm is measured by the chamber, except for the part lost by air absorption.

Measurements are first made, using the beam in its minimum-filter condition. Filters of aluminum, copper, or lead are then interposed in the beam up to the point where the beam is rendered sufficiently homogeneous, so that further additions of filters will not lower the air-absorption coefficient by an appreciable amount. This is illustrated (fig. 2) by the semilogarithmic plots of X-ray

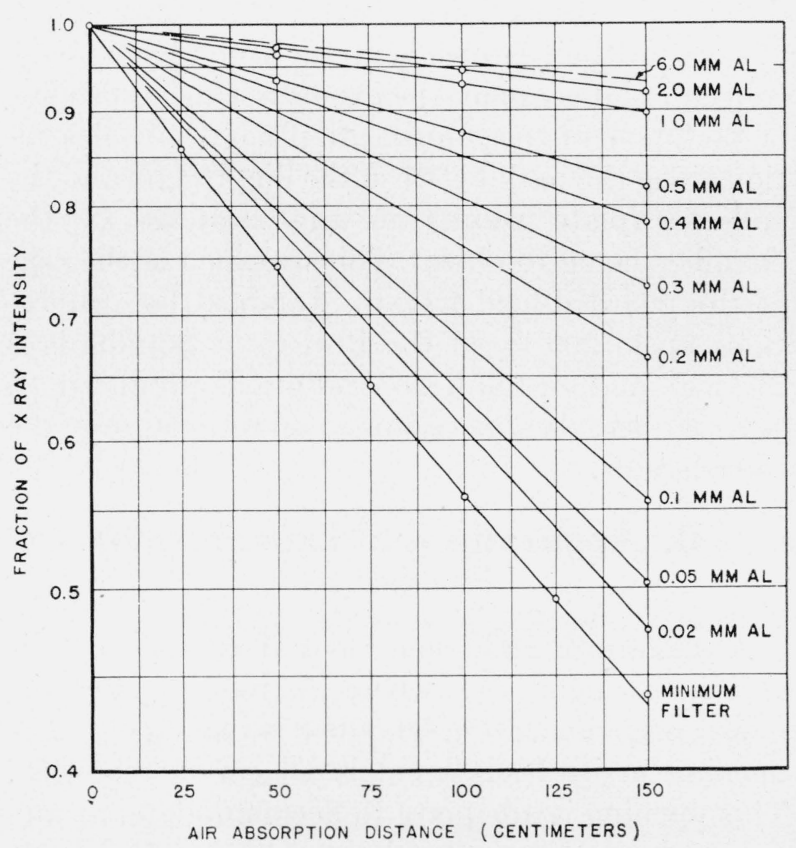

Figure 2. Effect of aluminum filtration on air absorption of 50-kv X-rays produced by beryllium-window X-ray tube with inherent filtration $1.5 \mathrm{~mm}$ Be. 
intensity as a function of the length of the absorbing air path for the $50 \mathrm{kv} \mathrm{X}$ rays from the beryllium-window tube. Here it is observed that filtrations in excess of $2 \mathrm{~mm}$ of aluminum will not greatly affect the air absorption. ${ }^{3}$ Similarly, it is found that for any voltage up to $200 \mathrm{kv}$, filtrations of $6 \mathrm{~mm}$ of $\mathrm{Al}, 0.2 \mathrm{~mm}$ of $\mathrm{Cu}$, or $0.1 \mathrm{~mm}$ of $\mathrm{Pb}$ are sufficient for the attainment of a practical lower limit to the air absorption.

These studies are made with $\mathrm{X}$ rays of $200 \mathrm{kv}$ and less, to voltages as low as transmission through filters will allow. Minimum-filter conditions allow observations on $\mathrm{X}$ rays as low as $7.5 \mathrm{kv}$ trom a beryllium-window tube. Even these $7.5-\mathrm{kv} \mathrm{X}$ rays show no great change in quality due to absorption in the air itself over the distance of observation, as indicated by a near straight-line semilogarithmic plot in figure 3. Since the beam is effectively

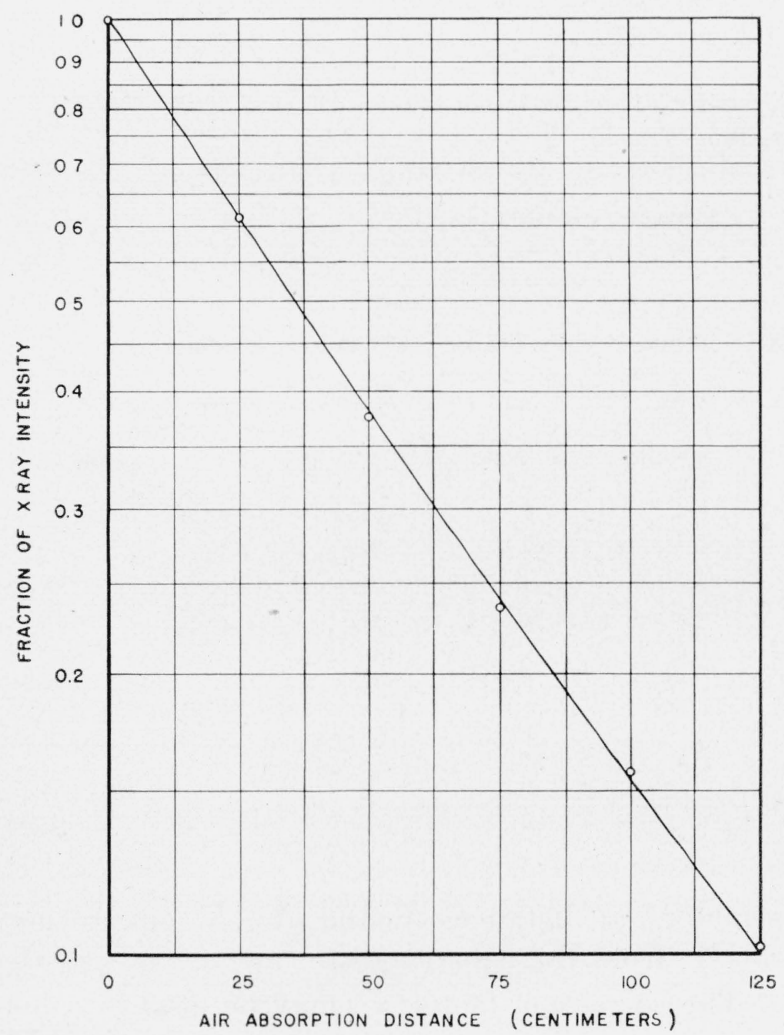

Figure 3. Air absorption of $7.5-k v$ X-rays produced by beryllium-window tube with inherent filtration $1.5 \mathrm{~mm}$ Be.

3 The curve for 6 -mm filtration was not observed at this voltage because of the extremely long exposure which would be necessary. At $100 \mathrm{kv}$, however, the difference between the $2-\mathrm{mm}$ and the 6 -mm curves is approximately 1 percent. The difference would not be greater than this in the case of $50-\mathrm{kv}$ $\mathrm{X}$-rays, for the same amount of filter would render the beam more homogeneous in the latter case. monochromatic, it is permissible to prepare tables of linear absorption coefficients involving a single term ${ }^{4}$ for air under normal atmospheric conditions, $\left(760 \mathrm{~mm}\right.$ of mercury pressure and $22^{\circ} \mathrm{C}$ ), these to be applied over short distances.

Tables 1, 2, and 3 give effective linear absorption coefficients, $\mu\left(\mathrm{cm}^{-1}\right)$ for air, where $\mu$ is used in the formula, $I_{\mathrm{X}}=I_{0} e^{-\mu X}, I_{X}$ being the intensity at a distance $X \mathrm{~cm}$ beyond the point where the original intensity, $I_{0}$, is measured. The X-ray beam is here considered to be parallel.

TABLE 1. Linear absorption coefficients for X-rays of air under atmospheric conditions obtained with berylliumwindow X-ray tube

\begin{tabular}{|c|c|c|c|c|c|}
\hline \multirow{3}{*}{ Voltage } & \multicolumn{5}{|c|}{ Absorption coefficient $(\mu)$} \\
\hline & \multirow{2}{*}{$\begin{array}{l}\text { Minimum } \\
\text { filtration } 1\end{array}$} & \multicolumn{4}{|c|}{ Added filtration } \\
\hline & & $\underset{\mathrm{Cu}}{0.05 \mathrm{~mm}}$ & $\underset{\mathrm{Cu}}{0.1 \mathrm{~mm}}$ & $\underset{\mathrm{Cu}}{0.2 \mathrm{~mm}}$ & $0.1 \mathrm{~Pb}$ \\
\hline$k v$ & $c m^{-1}$ & $\mathrm{~cm}^{-1}$ & $\mathrm{~cm}^{-1}$ & $\mathrm{~cm}^{-1}$ & $\mathrm{~cm}^{-1}$ \\
\hline $50 \ldots \ldots$ & $5.8 \times 10^{-3}$ & $3.5 \times 10^{-2}$ & $1.5 \times 10^{-3}$ & $0.5 \times 10^{-3}$ & $0.3 \times 10^{-3}$ \\
\hline $60 \ldots \ldots$ & 5. 6 & 3.1 & 1.2 & .4 & .3 \\
\hline $70 \ldots$ & 5.5 & 2.8 & 1.1 & .4 & .3 \\
\hline $80 \ldots$ & 5.3 & 2.5 & 1.0 & .4 & .3 \\
\hline $90 \ldots$ & 5.2 & 2. 2 & 0.9 & .3 & .3 \\
\hline $100 \ldots$ & 5.1 & 2.0 & .8 & .3 & .3 \\
\hline $120 \ldots$ & 4.8 & 1.6 & .7 & .3 & .3 \\
\hline $140 \ldots \ldots$ & 4. 6 & 1.3 & .6 & .3 & .3 \\
\hline $160 \ldots \ldots$ & 4.3 & 1.1 & .5 & .3 & .3 \\
\hline $180 \ldots$ & 4. 1 & 1. 0 & .5 & .3 & .3 \\
\hline $200 \ldots$ & 3.9 & 0.8 & .4 & .3 & .3 \\
\hline
\end{tabular}

${ }_{1}$ Minimum filtration is $1.5 \mathrm{~mm}$ of beryllium plus $119 \mathrm{~cm}$ of air.

Data in these tables are derived by calculating $\mu$ for air between $119 \mathrm{~cm}$ and $269 \mathrm{~cm}$ from the tube target. Errors due to change in quality of the X-rays will be involved in applying these data to determine intensities at great distances ${ }^{5}$ from the target, and, also, at distances a few centimeters from the target. However, within the range of approximately 1 to $3 \mathrm{~m}$ from the target, these coefficients may be applied with little error.

For ready reference, some air absorption correction factors have been prepared and are shown

4 To accurately specify the absorption of a heterogeneous beam, it is necessary to employ an expression that is the sum of exponential terms involving different absorption coefficients.

5 "Great distances", as here used, refers to the absorption by a sufficient quantity of air to reduce the intensity of the original beam by several half, value layers. However, reductions of the order of only one half-value layer, such as observed in this experiment (fig. 2), show very little quality dependence. 
TABLE 2. Linear absorption coefficients for $\mathrm{X}$ rays of air under atmospheric conditions obtained with beryllium-window $\mathrm{X}$-ray tube

\begin{tabular}{|c|c|c|c|c|c|c|c|c|}
\hline \multirow{3}{*}{ Voltage } & \multicolumn{8}{|c|}{ Absorption coefficient $(\mu)$} \\
\hline & \multirow{2}{*}{$\begin{array}{l}\text { Minimum } \\
\text { filtration } 1\end{array}$} & \multicolumn{7}{|c|}{ Added filtration } \\
\hline & & $0.05 \mathrm{~mm} \mathrm{Al}$ & $0.2 \mathrm{~mm} \mathrm{Al}$ & $0.5 \mathrm{~mm} \mathrm{Al}$ & $1.0 \mathrm{~mm} \mathrm{Al}$ & $2.0 \mathrm{~mm} \mathrm{Al}$ & $4.0 \mathrm{~mm} \mathrm{Al}$ & $6.0 \mathrm{~mm} \mathrm{Al}$ \\
\hline 7.5 & $\begin{array}{c}c m^{-1} \\
20.5 \times 10^{-3}\end{array}$ & $\mathrm{~cm}^{-1}$ & $\mathrm{~cm}^{-1}$ & $c m^{-1}$ & $\mathrm{~cm}^{-1}$ & $c m^{-1}$ & $c m^{-1}$ & $c m^{-1}$ \\
\hline 10 & 12.9 & 9. $7 \times 10^{-3}$ & 8. $3 \times 10^{-3}$ & & & & & -1 \\
\hline 15 & 7.8 & $\ldots$ & & (2) & & & $\therefore$ & \\
\hline $20 \ldots$ & 6.9 & 5.3 & 3.9 & 2. $5 \times 10^{-3}$ & ........... & - n & ........ & $-\ldots$ \\
\hline 30 & 6.1 & 4.9 & 3. 3 & 1.8 & $0.9 \times 10^{-3}$ & $0.8 \times 10^{-3}$ & (n) & -......... \\
\hline $40 \ldots$ & 5.9 & 4.8 & 3.0 & 1.5 & .8 & .6 & & $\ldots . .$. \\
\hline $50 \ldots$ & 5.8 & 4.6 & 2.8 & 1.4 & .7 & .6 & $0.5 \times 10^{-3}$ & $0.4 \times 10^{-3}$ \\
\hline 60 & 5. 6 & 4.5 & 2. 7 & 1.3 & .7 & .6 & .5 & .4 \\
\hline 70 & 5.5 & 4.4 & 2. 6 & 1. 2 & .7 & .5 & .5 & .4 \\
\hline $80 \ldots$ & 5.3 & 4.3 & 2.5 & 1. 1 & .6 & .5 & .5 & .4 \\
\hline $90 \ldots$ & 5. 2 & 4.2 & 2.4 & 1.0 & .6 & .5 & .4 & .4 \\
\hline 100 & 5. 1 & 4.1 & 2.3 & 0.9 & .6 & .5 & .4 & .4 \\
\hline
\end{tabular}

${ }_{1}^{1}$ Minimum filtration is $1.5 \mathrm{~mm}$ of beryllium plus $119 \mathrm{~cm}$ of air.

TABLE 3. Linear absorption coefficients for $\mathrm{X}$ rays of air under atmospheric conditions obtained with cerium glass-window X-ray tube

\begin{tabular}{|c|c|c|c|c|c|c|}
\hline \multirow{3}{*}{ Voltage } & \multicolumn{6}{|c|}{ Absorption coefficient $(\mu)$} \\
\hline & \multirow{2}{*}{$\begin{array}{l}\text { Minimum } \\
\text { filtration }^{1}\end{array}$} & \multicolumn{5}{|c|}{ Added filtration } \\
\hline & & $0.5 \mathrm{~mm} \mathrm{Al}$ & $1.0 \mathrm{~mm} \mathrm{Al}$ & $2.0 \mathrm{~mm} \mathrm{Al}$ & $4.0 \mathrm{~mm} \mathrm{Al}$ & $6.0 \mathrm{~mm} \mathrm{Al}$ \\
\hline 20 & $\begin{array}{c}\mathrm{cm}^{-1} \\
3.2 \times 10^{-3}\end{array}$ & $\mathrm{~cm}^{-1}$ & $c m^{-1}$ & $\mathrm{~cm}^{-1}$ & $\mathrm{~cm}^{-1}$ & $\mathrm{~cm}^{-1}$ \\
\hline $30 \ldots$ & 2. 6 & 1. $3 \times 10^{-3}$ & $0.9 \times 10^{-3}$ & $0.8 \times 10^{-3}$ & & \\
\hline 40 & 2.2 & 1.1 & .8 & .6 & (n............ & 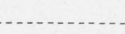 \\
\hline 50 & 2.1 & 1.0 & .7 & .6 & $0.5 \times 10^{-3}$ & $0.4 \times 10^{-3}$ \\
\hline $60 \ldots \ldots \ldots$ & 2.0 & .9 & .7 & .6 & .5 & .4 \\
\hline $70 \ldots \ldots$ & 1.9 & .9 & .7 & .5 & .5 & .4 \\
\hline $80 \ldots \ldots$ & 1.8 & .8 & .6 & .5 & .5 & .4 \\
\hline 90 & 1.8 & .8 & .6 & .5 & .4 & .4 \\
\hline 100 & 1.7 & .7 & .6 & .5 & .4 & .4 \\
\hline 110 & 1.6 & .7 & .6 & .5 & .4 & .4 \\
\hline 120 & 1.5 & .7 & .6 & .5 & .4 & .4 \\
\hline
\end{tabular}

1 Minimum filtration is $1.29 \mathrm{~mm}$ of cerium glass plus $119 \mathrm{~cm}$ of air.

in figures $4,5,6$, and 7 . For a parallel beam, the air absorption correction factor, $C$, is taken to be,

$$
C=\frac{I_{X}}{I_{0}}
$$

In the case of a diverging beam, it may be defined as,

$$
C=\frac{I_{X}^{\prime}}{I_{0}^{\prime}}\left(\frac{X_{0}+X}{X_{0}}\right)^{2}
$$

where $I_{0}^{\prime}$ and $I_{X}^{\prime}$ are the intensities measured by r-meter ${ }^{6}$ at distances $X_{0}$ and $X+X_{0} \mathrm{~cm}$, respectively, from the tube target.

The correction factor, $C$, may be used in calculating intensities at various points, where a thimble chamber ${ }^{6}$ measurement is made at one point only. Its application in field use is to determine the intensity at one position by air ionization measurement, calculate by inverse-square law the intensity to be expected at some distance farther from the

${ }^{6}$ John A. Victoreen, Medical physies, p. 1370-1382 (The Year Book Publishers, Inc., Chicago, Ill., 1944). 
source, if it were operating alone as a reducing factor; then, multiply this intensity by the air absorption correction factor to determine the true intensity. If the intensity is to be determined at some point closer to the source than the ionization measurement is made, the reciprocal of the air absorption correction factor will be used as the multiplying factor.

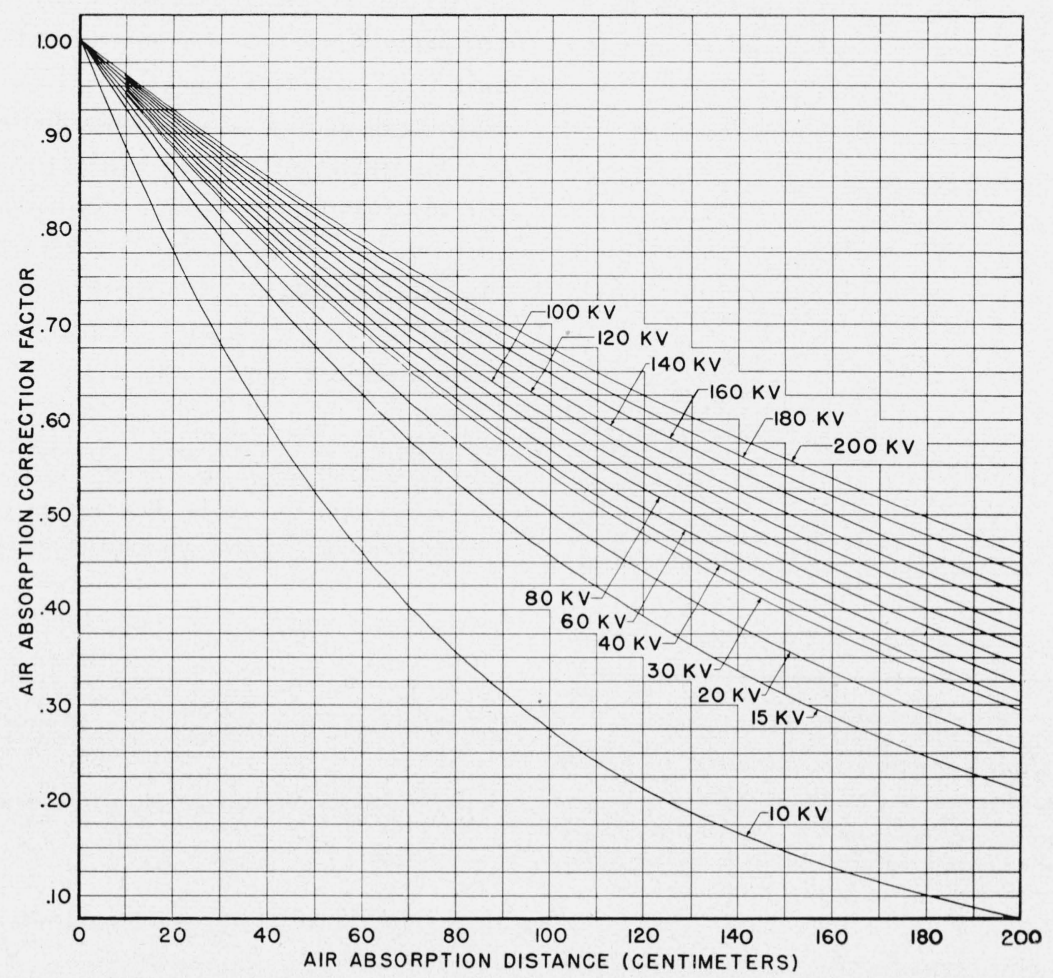

FIGURE 4. Air-absorption reduction in intensity of minimum-filter X-ray beam from beryllium-window tube with inherent filtration $1.5 \mathrm{~mm}$ Be.

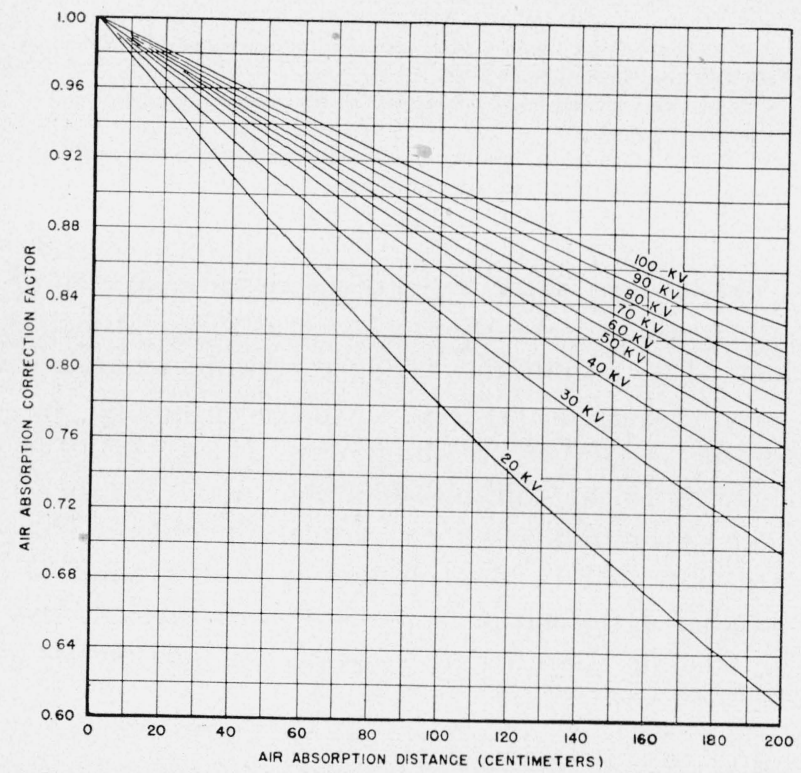

Figure 5. Air-absorption reduction in intensity of $X$-ray beam filtered by $0.5 \mathrm{~mm}$ of $\mathrm{Al}$.

(Inherent filtration of X-ray tube used is $1.5 \mathrm{~mm} \mathrm{Be}$.)

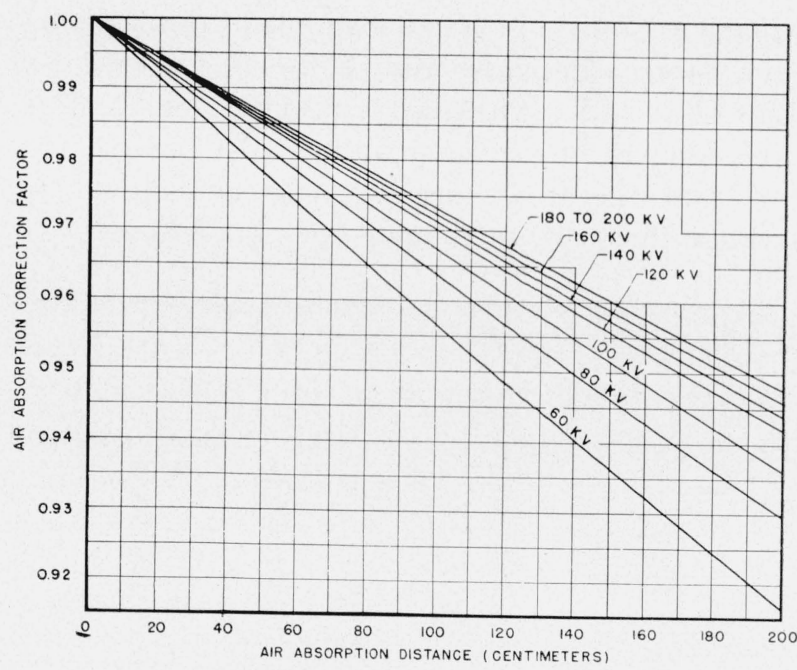

Figure 6. Air-absorption reduction in intensity of X-ray beam filtered by $0.2 \mathrm{~mm}$ of $\mathrm{Cu}$.

(Inherent filtration of X-ray tube used is $1.5 \mathrm{~mm} \mathrm{Be}$.) 


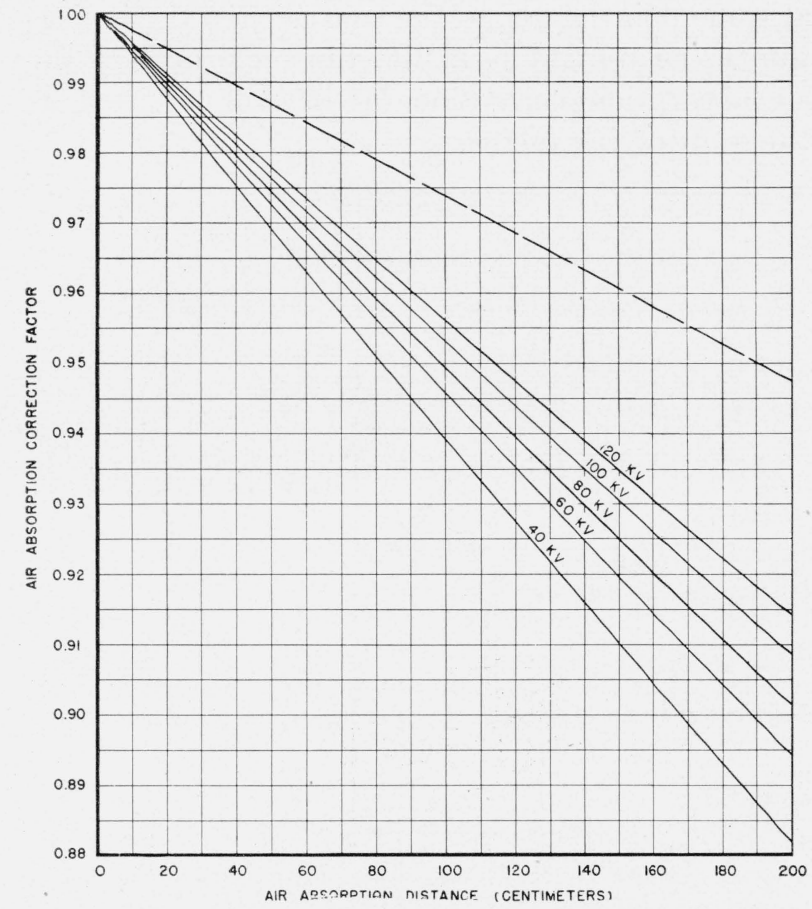

Figure 7. Air-absorption reduction in intensity of X-ray beam filtered by $2.0 \mathrm{~mm}$ of $\mathrm{Al}$ (solid lines).

Dashed line indicates reduction produced by $0.1 \mathrm{~mm}$ of $\mathrm{Pb}$ filter for X-rays of all qualities from 50 to $200 \mathrm{kv}$. (Inherent filtration of X-ray tube used is $1.5 \mathrm{~mm} \mathrm{Be.)}$

In cases where the graphs do not cover the conditions desired, the air absorption correction factor may be calculated, using the absorption coefficients given in tables 1,2 , and 3 , and the equation, $C=e^{-\mu X}$. As an example of this calculation, table 3 indicates that $\mu$ for $40 \mathrm{kv}$ with 1.0 $\mathrm{mm} \mathrm{Al}$ of added filtration is $0.8 \times 10^{-3} \mathrm{~cm}^{-1}$. $C$ is then defined for arbitrary values of $X$ beyond 119 $\mathrm{cm}$ from the tube target. It is convenient to arrange the work in tabular form, as follows:

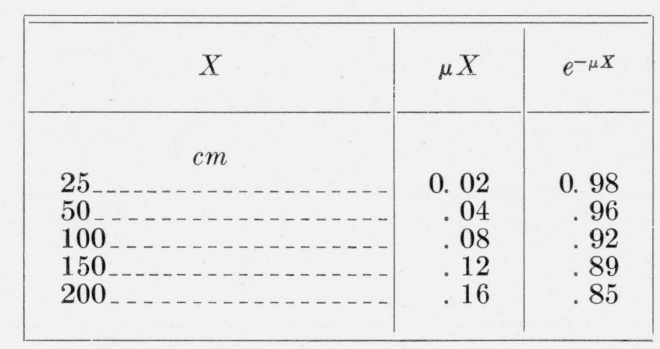

\section{Free-Air Chamber Versus Thimble- Chamber Air-Absorption Data}

That the air absorption factors determined with the free-air chamber are applicable also to thimble chamber use is indicated by reference to table 4 . In this case, the limiting diaphragm is removed and a 25-r thimble chamber is placed at the midpoint of the collector plates of the freeair chamber, the latter chamber being here used only as a vehicle for transport of the thimble chamber. Data obtained are at $90 \mathrm{kv}$ with no filtration other than $1.29 \mathrm{~mm}$ of cerium glass, the tube window thickness.

TABLE 4. Comparison of air absorption data for 90-kv Y-rays obtained by thimble ionization chamber with those obtained by free-air ionization chamber under minimum filter condition (1.29 $\mathrm{mm}$ of cerium glass)

\begin{tabular}{|c|c|c|c|}
\hline $\begin{array}{c}\text { Distance, X, } \\
\text { of air } \\
\text { absorption 1 }\end{array}$ & $\begin{array}{c}\text { Intensity, as } \\
\text { measured by } \\
\text { thimble } \\
\text { chamber }\end{array}$ & $\begin{array}{c}\text { Thimble chamber } \\
\text { intensity calcu- } \\
\text { lated to indicate } \\
\text { air absorption } \\
\text { only }{ }^{3}\end{array}$ & $\begin{array}{c}\text { Intensity as } \\
\text { measured by } \\
\text { free-air } \\
\text { chamber }\end{array}$ \\
\cline { 1 - 2 }$c m$ & percent & percent & pecrent \\
0 & 100 & 100 & 100 \\
25 & 64.9 & 95.1 & 94.9 \\
50 & 44.9 & 90.7 & 91.0 \\
75 & 32.5 & 86.4 & 87.0 \\
100 & 24.5 & 83.1 & 83.1 \\
125 & 18.9 & 79.4 & 80.3 \\
150 & 15.0 & 76.7 & 77.7 \\
\hline
\end{tabular}

${ }^{1} X$ is the ionization chamber travel distance, the zero position of which is $119 \mathrm{~cm}$ from the X-ray tube target.

2 This includes inverse-square reduction in intensity superimposed upon air absorption reduction.

${ }_{3}$ The observed thimble chamber intensity times $(119+X / 119)^{2}$ yields an intensity indicating the air absorption reduction only.

These data show reductions in intensity due both to the inverse-square law and to air absorption. The minimum target-to-thimble-chamber distance used is $119 \mathrm{~cm}$. Multiplication of the thimble chamber readings by $(119+X / 119),{ }^{2}$ where $X$ is the thimble-chamber travel distance, yields data indicating air absorption only. The data obtained in this manner with the thimble chamber agree within a percent with those using the free-air chamber as described in section III. 
In the case of soft X-rays, thimble-chamber measurement of the ratio of intensities between two points may be made without appreciable error, because there is no significant selective absorption of the soft components of the X-rays in traversing the amounts of air considered. The calibration of thimble chambers for soft X-rays, however, will be in error, the readings being less than those for hard X-rays, because there is appreciable absorption of the soft rays in the thimble chamber wall. The subject of such calibrations for soft X-rays will be discussed in another paper now in preparation.

The authors thank John H. Baltrukonis for obtaining much of the data reported above.

Washington, September 15, 1947. 